\title{
HYPOCOMPLEMENTEMIC URTICARIAL VASCULITIS AS AN INITIAL MANIFESTATION OF PRIMARY SJOGREN'S SYNDROME
}

Cipriano Reis Gama ${ }^{1, *}$, Victor Matheus Ostrovski Souza Santos ${ }^{1}$, Janaína Baggio', Vanessa Posener de Andrade, Henrique Ayres Mayrink Giardini', Lissiane Karine Guedes', Rosa Maria Rodrigues Pereira'

1. Universidade de São Paulo, São Paulo (SP), Brazil.

*Corresponding author: cipriano.gama@hc.fm.usp.br

\section{BACKGROUND}

Hypocomplementemic urticarial vasculitis (HUV) is a rare condition that is characterized by urticarial lesions, which usually last for more than 24 hours, developed with pigmented or purpuric lesions and are associated with hypocomplementemia. Forty percent of patients show abdominal pain. The literature shows that the association with Sjogren's syndrome is uncommon. As with systemic lupus erythematosus (SLE), the pathophysiology of HUV involves the formation of immune complexes, but in most cases, patients do not meet the criteria for SLE and are anti-DNA negative. Half of the cases have attacks of angioedema due to the consumption of C1q.

\section{CASE REPORT}

Female patient, 45 years old, followed up at the dermatology service due to drug-induced skin disorders, angioedema and contact dermatitis. She presented recurrent episodes of urticaria and purpura initially in the lower limbs, with progression to the upper limbs and an episode of anaphylaxis (Figs. 1, 2 and 3). She developed abdominal pain associated with nausea, vomiting and selflimited hematochezia. It associated weight loss, about $10 \mathrm{~kg}$, in the last year. She denied sicca syndrome. In research, homogeneous antinuclear antibody (ANA) 1:320, Anti-SSA/Ro in high titers (> $200 \mathrm{U}$ ), complement consumption (C3: $58 \mathrm{mg} / \mathrm{dL}, \mathrm{C4}: 4.8 \mathrm{mg} / \mathrm{dL}$ ) were observed. Non-reactive Anti-DNA, Anti-SSB/La, ANCA, anti-SM, anticardiolipin, anti-beta-2 glycoprotein, lupus anticoagulant, and, negative cryoglobulin screening. Skin biopsy with leukocytoclastic vasculitis, with negative immunofluorescence. Salivary gland biopsy with mild nonspecific lymphoplasmacytic infiltrate - focal score: 1 focus $/ 4 \mathrm{~mm}^{2}$. Diagnosis of hypocomplementemic urticarial vasculitis associated with primary Sjogren's syndrome was done. Azathioprine and corticosteroid pulse therapy were started, the patient evolved with global improvement. It is under investigation for acquired angioedema - awaiting dosage of $\mathrm{C} 1$ esterase inhibitor and research for anti $\mathrm{C} 1$ esterase antibodies.

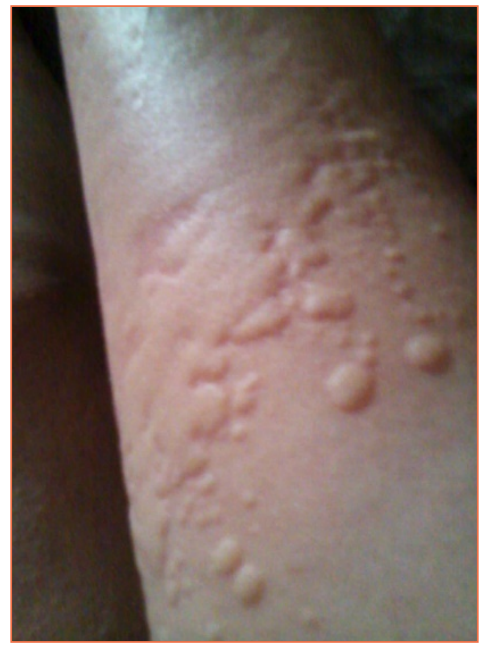

Figure 1. Papular urticaria in the forearm. 


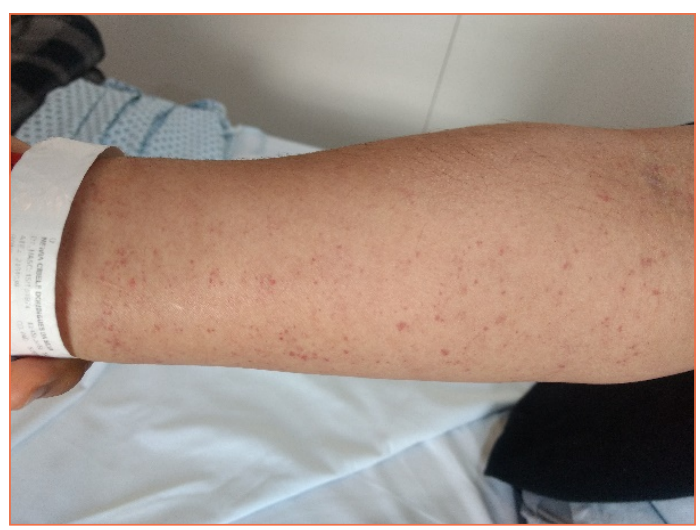

Figure 2. Purple in upper limbs.

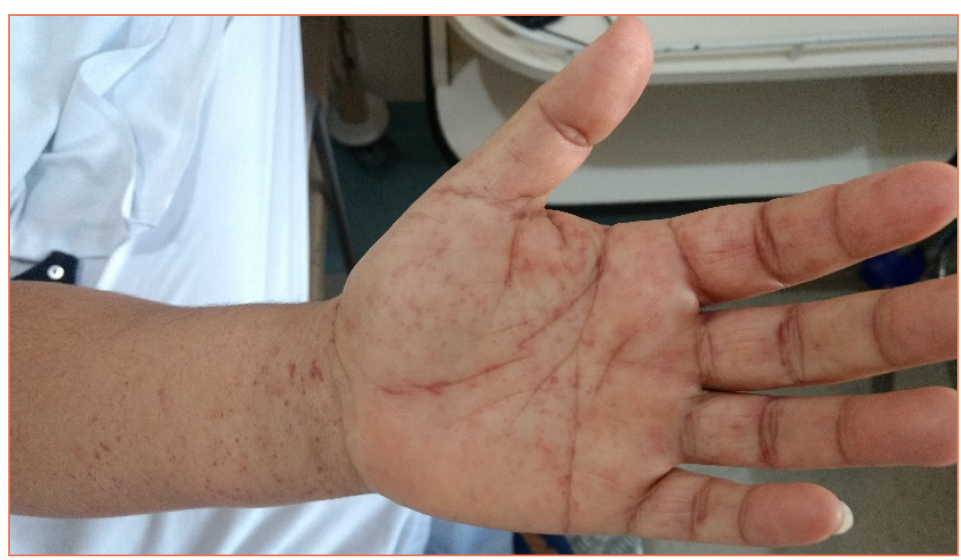

Figure 3. Purple in upper limbs.

\section{CONCLUSION}

It is essential that the physician is attentive to the diagnosis of hypocomplementemic urticarial vasculitis when faced with chronic urticaria, and although it is poorly described, primary Sjogren's syndrome must be considered as an associated condition, especially if anti-SSA/Ro is positive. This characterization will have a prognostic influence on patient follow-up. 